\title{
Rapid and Practical Screening Method for the Detection of Colistin-Resistant Bacteria in Food
}

\author{
Hanh $\mathrm{Vu}^{1,2}$, Cornelia Appiah-Kwarteng1, Kaori Tanaka ${ }^{1,2}$, Ryuji Kawahara ${ }^{3}$, Diep Thi Khong ${ }^{4}$, \\ Thang Nam Nguyen", Hoa Thi Tran, Chinh Dang Van ${ }^{4}$, Phuc Do Nguyen ${ }^{5}$ and Yoshimasa \\ Yamamoto ${ }^{1,2 *}$ \\ ${ }^{1}$ Life Science Research Center, Gifu University, Japan \\ ${ }^{2}$ The United Graduate School of Drug Discovery and Medical Information Sciences, Gifu University, Japan \\ ${ }^{3}$ Department of Microbiology, Osaka Institute of Public Health, Japan \\ ${ }^{4}$ Center of Medical-Pharmaceutical Science and Technology Services, Thai Binh University of Medicine and Pharmacy, Vietnam \\ ${ }^{5}$ Institute of Public Health, Ho Chi Minh City, Vietnam
}

*Corresponding author: Yoshimasa Yamamoto, The United Graduate School of Drug Discovery and Medical Information Sciences,

Gifu University, 1-1 Yanagido, Gifu, Japan

\section{ARTICLE INFO}

Received: 㓞 November 01, 2021

Published: 慧 November 15, 2021

Citation: Hanh Vu, Cornelia Appiah-Kwarteng, Kaori Tanaka, Ryuji Kawahara, Yoshimasa Yamamoto, et al., Rapid and Practical Screening Method for the Detection of Colistin-Resistant Bacteria in Food. Biomed J Sci \& Tech Res 40(1)-2021. BJSTR. MS.ID.006380.

\author{
ABSTRACT
}

We developed a rapid and practical screening method for simultaneously detecting both Escherichia coli and bacteria harboring the $m c r-1$ colistin resistance gene using high-speed real-time polymerase chain reaction with specific TaqMan probes. The entire procedure, from sample processing to the final result, was performed within 1 h. The practical utility of this method was verified by analyzing 27 retail meat samples for the presence of colistin-resistant bacteria. The results indicated the potential of this method for the convenient and rapid screening of food items to detect contamination with mcr-1-positive bacteria, which can be especially useful for on-site testing in developing countries.

Keywords: Colistin-Resistant Bacteria; Food; Mcr-1; Rapid Screening Method; RealTime Polymerase Chain Reaction

\section{Introduction}

Colistin is recognized as one of the few remaining available antibiotics for the treatment of intractable infections caused by multidrug-resistant Gram-negative bacteria [1]. Recent studies have shown that bacteria carrying the $\mathrm{mor}$ gene, which confers colistin resistance to most members of the Enterobacteriaceae, are widely disseminated, particularly in Asia [2,3]. Since colistin is widely used in animal husbandry [4], the spread of colistin-resistant (CR) bacteria in communities via livestock food is a potential risk factor. Moreover, CR bacteria are often found in animals and animalfood [5-7]; thus, monitoring CR bacteria in animal-food is essential. However, the conventional culture method [8] for detecting CR bacteria in food is laborious and time-consuming. Rapid detection of colistin resistance genes at the research level is now possible using the SYBR green method [9], but its widespread practicality is limited due to the need for complex steps and equipment involved in DNA extraction from samples and determination of result specificity. To overcome this limitation, we here report a simple, rapid, and practical detection method of Escherichia coli harboring $m c r-1$, as a representative CR bacterium, using a highspeed real-time polymerase chain reaction (PCR) kit. We further verified the utility of this method for detecting CR bacteria in retail meat samples. Although a real-time PCR assay for the detection 
of $m c r$ genes from bacterial isolates has already been established, this newly proposed detection method holds practical relevance for widespread use, as the entire procedure, from food sample processing to the final result, can be completed within only $1 \mathrm{~h}$.

\section{Materials and Methods}

A total of 27 retail meat samples, including pork and chicken, were collected from 10 markets (two supermarkets and eight local traditional markets) in Vietnam and five supermarkets in Japan during November and December 2019. None of the eight traditional markets in Vietnam maintained a refrigerator for meat preservation. In contrast, the two supermarkets in Vietnam and all five supermarkets in Japan had refrigerators for food storage. Each sample was collected from one meat type per market. Bacterial cultures and DNA extraction were performed on the collection day. Ten grams of each meat sample were placed in a stomacher bag (AS ONE, Osaka, Japan) containing $90 \mathrm{~mL}$ buffered peptone water. The samples were hand-homogenized for 2 min. The resulting homogenate was inoculated on CHROMagar COL-APSE (CHROMagar, Paris, France), a selective medium for CR Gram-negative bacteria, and cultured at $37{ }^{\circ} \mathrm{C}$ for $24 \mathrm{~h}$. CR E. coli-like colonies were distinguished based on colony color (dark pink to reddish) after cultivation [8,10]. A representative colony was isolated by sub-culturing on MacConkey agar, and bacterial identification was performed. The colistin minimum inhibitory concentration (MIC) was estimated, and colistin resistance genes ( $m c r-1$ to -5 ) were detected by multiplex PCR as described previously $[6,11]$.

In parallel, DNA was extracted from $1 \mathrm{~mL}$ of the homogenate using the Kaneka Easy DNA Extraction Kit version 2 (Kaneka, Tokyo, Japan). The presence of E. coli and the colistin resistance gene $m c r-1$ in the DNA extracts was determined by real-time PCR using a mobile PCR device, PicoGene PCR1100 (Nippon Sheet Glass, Tokyo, Japan). PCR primers and TaqMan probes for realtime PCR detection of E. coli $16 \mathrm{~S}$ rRNA and $m c r-1$ were prepared as described previously (Table 1) [12]. Details regarding the realtime PCR, including PCR mixtures and thermal cycling conditions, are provided in Tables $2 \& 3$, respectively. The DNA extract of the CR E. coli strain (E362) [6] carrying $m c r-1$ was utilized as a positive control in PCR. The entire 50 PCR cycles were completed within only 21 min. Moreover, the real-time PCR device could simultaneously measure fluorescence at three different wavelengths for the same sample. Two fluorescent dye-labeled TaqMan probes (Integrated DNA Technologies, Singapore), Cy5 for E. coli 16S rRNA and FAM for $m c r-1$, were used for each sample. The entire protocol is outlined in Figure 1. Figure 2 shows representative real-time PCR profiles of the samples.

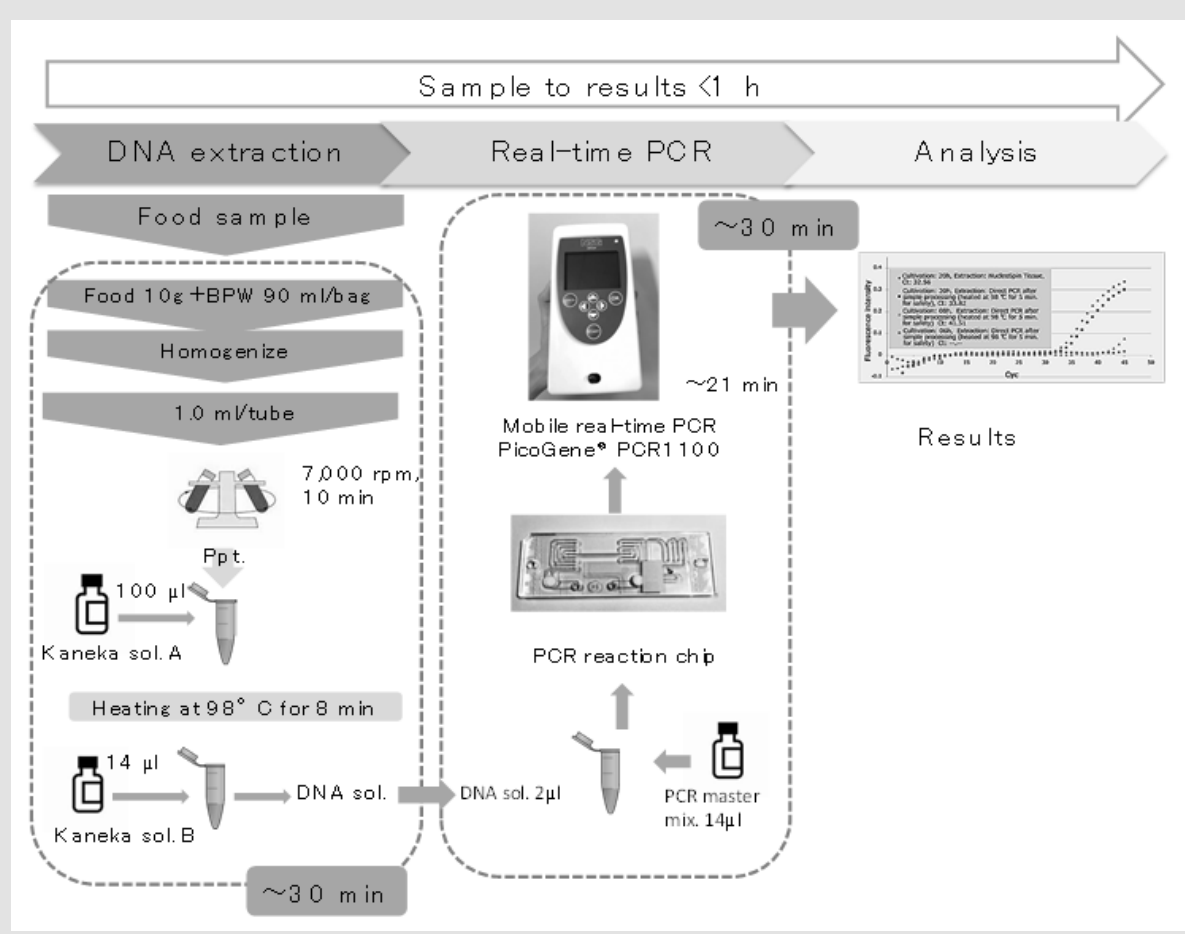

Figure 1: Outline of the screening protocol using mobile real-time PCR PicoGene ${ }^{\circledR}$ PCR1100. BPW, buffered peptone water. 
Table 1: Primers and probes used in the study [12].

\begin{tabular}{|c|c|}
\hline Amplified gene & Primer sequences (5'-3') \\
\hline 16S rRNA E. coli forward & TGGAGCATGTGGTTTAATTCGA \\
\hline 16S rRNA E. coli reverse & TGCGGGACTTAACCCAACA \\
\hline$m c r-1$ forward & TCAGCAGTCATTATGCCAG \\
\hline$m c r-1$ reverse & ATACTCAATACTGGCAAGC \\
\hline Probes & Sequences (5'-3') \\
\hline 16S rRNA E. coli probe & Сy5-CACGAGCTGACGACAACCATGCA-BHQ2 \\
\hline$m c r-1$ probe & $\begin{array}{l}\text { FAM-TCGCGTGCATAAGCCGCTGCGTAGCT- } \\
\text { BHQ1 }\end{array}$ \\
\hline
\end{tabular}

Table 2: Real-time PCR assay reaction mixture.

\begin{tabular}{|c|c|c|}
\hline \multirow[b]{3}{*}{ Master mix } & 1x KAPA Plant PCR Buffer* & $8 \mu \mathrm{L}$ \\
\hline & $25 \mathrm{mM} \mathrm{MgCl} 2$ & $0.64 \mu \mathrm{L}$ \\
\hline & $20 \mu \mathrm{M} \mathrm{mcr-1}$ primers & $1.28 \mu \mathrm{L}$ \\
\hline \multirow{4}{*}{$(14 \mu \mathrm{L})$} & $20 \mu \mathrm{M}$ E. coli $16 \mathrm{~S}$ rDNA primers & $1.28 \mu \mathrm{L}$ \\
\hline & $10 \mu \mathrm{M}$ mcr-1 FAM-probe & $0.32 \mu \mathrm{L}$ \\
\hline & $10 \mu \mathrm{M}$ E. coli $16 \mathrm{~S}$ rRNA Cy5-probe & $0.32 \mu \mathrm{L}$ \\
\hline & KAPA3G Plant DNA polymerase* & $2.5 \mathrm{U} / 1 \mu \mathrm{L}$ \\
\hline \multicolumn{2}{|c|}{ Template DNA extracts } & $2 \mu \mathrm{L}$ \\
\hline \multicolumn{2}{|r|}{ Total } & $16 \mu \mathrm{L}$ \\
\hline
\end{tabular}

Note: *NIPPON Genetics, Tokyo, Japan

Table 3: Real-time PCR cycling conditions.

\begin{tabular}{|c|c|}
\hline Step 1 & $95^{\circ} \mathrm{C} \times 5 \mathrm{~s}$ \\
\hline Step 2 & {$\left[95^{\circ} \mathrm{C} \times 3 \mathrm{~s} \rightarrow 60^{\circ} \mathrm{C} \times 15 \mathrm{~s}\right] \times 50$ cycles } \\
\hline
\end{tabular}

Table 4: Detection of colistin-resistant bacteria in food.

\section{Results and Discussion}

The detection sensitivity of the method was assessed using pork meat samples spiked with an mcr-1-positive E. coli strain culture. The lower limit of mcr-1-E. coli detection for the entire method, from DNA extraction to detection by real-time PCR, was 7 $\times 10^{2} \mathrm{CFU} / \mathrm{g}$; however, a minimum of $7 \times 10^{3} \mathrm{CFU} / \mathrm{g}$ was required for quantification using a linear correlation. In the validation study using retail meat samples, CR E. coli-like bacteria were detected using the culture-based method in eight out of ten chicken and in three out of seven pork samples purchased in Vietnam (Table 4). The semi-quantitative levels of CR bacteria in these samples were in the range $10^{3}-10^{8} \mathrm{CFU} / \mathrm{g}$ (Table 4). All representative CR E. coli isolates from each sample were confirmed to be resistant to colistin (MIC $\geq 4 \mu \mathrm{g} / \mathrm{mL}$ ) and possessed $m c r-1$ but not $m c r-2$ to -5 , except for the $\mathrm{H}$-E market pork sample, which harbored $m c r-3$ in addition to $m c r-1$, as determined by multiplex PCR. No samples from the Japanese supermarkets were contaminated with CR bacteria. All samples, except for the H-E market pork sample, that were positive via the culture-based method were also positive by real-time PCR (Table 4). Some culture-negative samples such as H-B market pork, T-B market chicken, T-B market pork, and T-E market chicken were PCR-positive. Such contradictory results may be attributed to the features of the real-time PCR method and its ability to detect $\mathrm{mcr}-1$ even in dead cells and/or non-E. coli cells. In contrast, a pork sample from the H-E market showed CR E. coli colonies after culturing but tested negative for $m c r-1$ by real-time PCR. Such discrepant cases could be due to a low level of $m c r$-1-positive bacteria below the detection limit of the real-time PCR method or the presence of bacteria expressing non-mor CR determinants [13].

\begin{tabular}{|c|c|c|c|c|c|c|c|}
\hline \multirow{3}{*}{ Location } & \multirow{3}{*}{ Market } & \multirow{3}{*}{$\begin{array}{c}\text { Presence } \\
\text { of meat } \\
\text { refrigerator }\end{array}$} & \multirow{3}{*}{ Sample } & \multicolumn{2}{|c|}{ Detection on CHROMagar COL-APSE } & \multicolumn{2}{|c|}{ mcr-1-real-time PCR } \\
\hline & & & & \multirow{2}{*}{$\begin{array}{c}\text { Colistin-resistant } \\
\text { bacteria detection }\end{array}$} & mcr- & \multirow{2}{*}{$\begin{array}{l}\text { Detection of } \\
\quad m c r-1\end{array}$} & \multirow{2}{*}{$\begin{array}{l}\text { Quantitative } \\
\text { level }^{\text {c }}\end{array}$} \\
\hline & & & & & Escherichia coli $^{b}$ & & \\
\hline \multirow{10}{*}{$\begin{array}{l}\text { Ho Chi Minh, } \\
\text { Vietnam }\end{array}$} & \multirow{2}{*}{$\mathrm{H}-\mathrm{A}$} & \multirow{2}{*}{ Yes } & Chicken & ++ & + & + & $8.5 \times 10^{3}$ \\
\hline & & & Pork & - & - & - & $-d$ \\
\hline & \multirow{2}{*}{$\mathrm{H}-\mathrm{B}$} & \multirow{2}{*}{ No } & Chicken & +++ & + & + & $9.8 \times 10^{5}$ \\
\hline & & & Pork & - & - & + & $\mathrm{ND}^{\mathrm{e}}$ \\
\hline & \multirow{2}{*}{$\mathrm{H}-\mathrm{C}$} & \multirow{2}{*}{ No } & Chicken & ++ & + & + & $9.8 \times 10^{5}$ \\
\hline & & & Pork & + & + & + & $4.1 \times 10^{4}$ \\
\hline & \multirow{2}{*}{ H-D } & \multirow{2}{*}{ Yes } & Chicken & ++ & + & + & ND \\
\hline & & & Pork & - & - & - & - \\
\hline & \multirow{2}{*}{$\mathrm{H}-\mathrm{E}$} & \multirow{2}{*}{ No } & Chicken & +++ & + & + & $1.1 \times 10^{8}$ \\
\hline & & & Pork & + & + & - & - \\
\hline
\end{tabular}




\begin{tabular}{|c|c|c|c|c|c|c|c|}
\hline \multirow{7}{*}{$\begin{array}{c}\text { Thai Binh, } \\
\text { Vietnam }\end{array}$} & \multirow{2}{*}{ T-A } & \multirow{2}{*}{ No } & Chicken & ++ & + & + & $1.9 \times 10^{4}$ \\
\hline & & & Pork & ++ & + & + & ND \\
\hline & \multirow{2}{*}{ T-B } & \multirow{2}{*}{ No } & Chicken & - & - & + & $1.9 \times 10^{4}$ \\
\hline & & & Pork & - & - & + & ND \\
\hline & $\mathrm{T}-\mathrm{C}$ & No & Chicken & ++ & + & + & $1.9 \times 10^{4}$ \\
\hline & T-D & No & Chicken & ++ & + & + & $9.1 \times 104$ \\
\hline & T-E & No & Chicken & - & - & + & $9.1 \times 104$ \\
\hline \multirow{2}{*}{ Gifu, Japan } & \multirow{2}{*}{ G-A,B,C,D,E } & \multirow{2}{*}{ Yes } & Chicken $(5)^{\mathrm{f}}$ & - & - & - & - \\
\hline & & & Pork $(5)^{\mathrm{f}}$ & - & - & - & - \\
\hline
\end{tabular}

Note:

a. Semi-quantitative level of colistin-resistant bacteria colonies grown on a CHROMagar COL-APSE agar plate ranging from - to +++ . -, no colonies; +, dozens of colonies; ++, hundreds of colonies; +++ , above the countable range.

b. Presence of mcr-E. coli identified by the culture-based method and multiplex PCR.

c. Number of bacteria harboring mcr-1 (E32 positive control strain equivalent) per gram of sample.

d. Negative in real-time PCR.

e. ND: not determined; levels below the real-time PCR linear range.

f. Total number of samples tested.

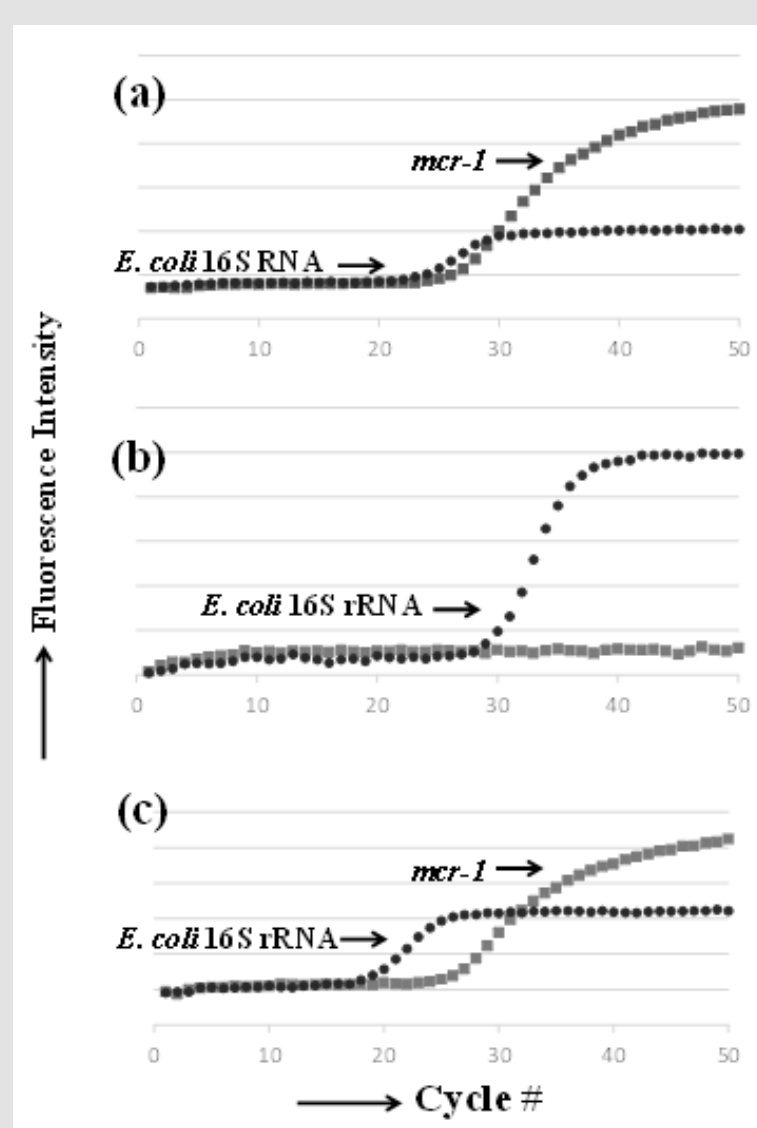

Figure 2: Representative plots obtained from real-time PCR amplification of mcr-1 and E. coli 16S rRNA genes in meat samples.
a) Positive control, $m c r-1$ E. coli.
b) mcr-1-negative pork sample, H-A market pork.
c) mor-1-positive chicken sample, H-E market chicken.

The new method presented herein detects the target gene and facilitates quantitative analysis. In addition, the method using TaqMan probes has high detection specificity, and is simple because it does not require specificity verification by melting curve analysis, even for one-step extracted DNA from food. The results output the ratio of bacteria carrying $m c r-1$ to the total number of $E$. coli cells, which may be mcr-1-positive or -negative bacteria (Figure 2). The detected quantitative $m c r-1$ levels were higher than the CR $E$. coli-like bacterial levels determined via the culture-based method because the real-time PCR method detects all $m c r-1$ regardless of bacterial species. The quantitative linear range detected via realtime PCR was between $10^{3}$ and $10^{6} \mathrm{CFU} / \mathrm{g}$. Although the detected signal was below the quantitative linear range limit in some samples, they were still considered to have positive results via realtime PCR. The approach described in this study provides limited information regarding the degree of contamination; nevertheless, the developed method is reliable and practical owing to a short processing time, enabling the rapid screening of contaminating bacteria with $m c r-1$ in food.

\section{Conclusion}

A new rapid and practical screening method was developed for detecting CR E. coli in food samples. The developed method is advantageous because it is easy to perform, has a short processing time, and provides reliable results that are consistent with those obtained by traditional methods.

\section{Declarations}

\section{Ethics Approval and Informed Consent}

Not applicable. 


\section{Consent for Publication}

Not applicable.

\section{Competing Interests}

This study was conducted using a mobile PCR device, PicoGene PCR1100, provided by Nippon Sheet Glass, Tokyo, Japan. There were no competing financial interests or personal relationships that could have influenced the work reported in this paper.

\section{Funding}

This work was supported by the Japan Society for the Promotion of Science KAKENHI (grant number 20H00561).

\section{Authors' Contributions}

HV participated in the study design, sample collection, and real-time PCR assay, and drafted the manuscript. CA-K performed the real-time PCR assay. KT participated in the study design. RK performed PCR assays and microbial analysis. DTK, TNN, HTT, CDV, and PDN contributed to sample collection and bacterial cultures. YY contributed to the study design, supervised data collection, and drafted the manuscript. All authors read and approved the final manuscript.

\section{Acknowledgment}

Not applicable.

\section{Availability of Data and Materials}

The datasets used and/or analyzed in this study are available from the corresponding author on reasonable request.

\section{References}

1. Giamarellou H, Poulakou G (2009) Multidrug-resistant gram-negative infections: what are the treatment options? Drugs 69(14): 1879-1901.

2. Shen Y, Zhou H, Xu J, Wang Y, Zhang Q et al. (2018) Anthropogenic and environmental factors associated with a high incidence of mcr-1 carriage in humans across China. Nat Microbiol 3(9): 1054-1062.

\section{ISSN: 2574-1241}

DOI: $10.26717 /$ BJSTR.2021.40.006381

Yoshimasa Yamamoto. Biomed J Sci \& Tech Res

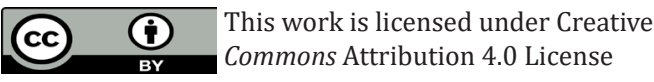

Submission Link: https://biomedres.us/submit-manuscript.php
3. Yamamoto Y, Kawahara R, Fujiya Y, Sasaki T, Hirai I, et al. (2018) Wide dissemination of colistin-resistant Escherichia coli with the mobile resistance gene $\mathrm{mcr}$ in healthy residents in Vietnam. J Antimicrob Chemother 74(2): 523-524.

4. Rhouma M, Beaudry F, Letellier A (2016) Resistance to colistin: what is the fate for this antibiotic in pig production? Int J Antimicrob Agents 48(2): 119-126.

5. Kawahara R, Fujiya Y, Yamaguchi T, Khong DT, Nguyen TN, et al (2019) Most domestic livestock possess colistin-resistant commensal Escherichia coli harboring $\mathrm{mcr}$ in a rural community in Vietnam. Antimicrob Agents Chemother 63(6): e00594-19.

6. Yamaguchi T, Kawahara R, Harada K, Teruya S, Nakayama T, et al. (2018) The presence of colistin resistance genes $m c r-1$ and -3 in ESBL-producing Escherichia coli isolated from food in Ho Chi Minh City, Vietnam. FEMS Microbiol Lett 365(11): fny100.

7. Perez-Rodriguez F, Mercanoglu Taban B (2019) A state-of-art review on multi-drug resistant pathogens in foods of animal origin: risk factors and mitigation strategies. Front Microbiol 10: 2091.

8. Abdul Momin MHF, Bean DC, Hendriksen RS, Haenni M, Phee LM, et al. (2017) CHROMagar COL-APSE: a selective bacterial culture medium for the isolation and differentiation of colistin-resistant Gram-negative pathogens. J Med Microbiol 66(11): 1554-1561.

9. Tolosi R, Apostolakos I, Laconi A, Carraro L, Grilli G, et al. (2020) Rapid detection and quantification of plasmid-mediated colistin resistance genes ( $m c r-1$ to $m c r-5)$ by real-time PCR in bacterial and environmental samples. J Appl Microbiol 129(6): 1523-1529.

10. Thiry D, Berrah A, Evrard J, Duprez JN, Mainil JG, et al. (2019) Assessment of two selective agar media to isolate colistin-resistant bovine Escherichia coli: Correlation with minimal inhibitory concentration and presence of mcr genes. J Microbiol Methods 159: 174-178.

11. Wakabayashi Y, Sekizuka T, Yamaguchi T, Fukuda A, Suzuki M, et al. (2020) Isolation and plasmid characterisation of Salmonella enterica serovar Albany harboring $\mathrm{mcr}$-5 from retail chicken meat in Japan. FEMS Microbiol Lett 367(15): fnaa127.

12. Daniels JB, Campbell D, Boyd S, Ansari U, Lutgring J, et al. (2019) Development and validation of a clinical laboratory improvement amendments-compliant multiplex real-time PCR assay for detection of mor genes. Microb Drug Resist 25(7): 991-996.

13. Aghapour Z, Gholizadeh P, Ganbarov K, Bialvaei AZ, Mahmood SS, et al. (2019) Molecular mechanisms related to colistin resistance in Enterobacteriaceae. Infect Drug Resist 12: 965-975.

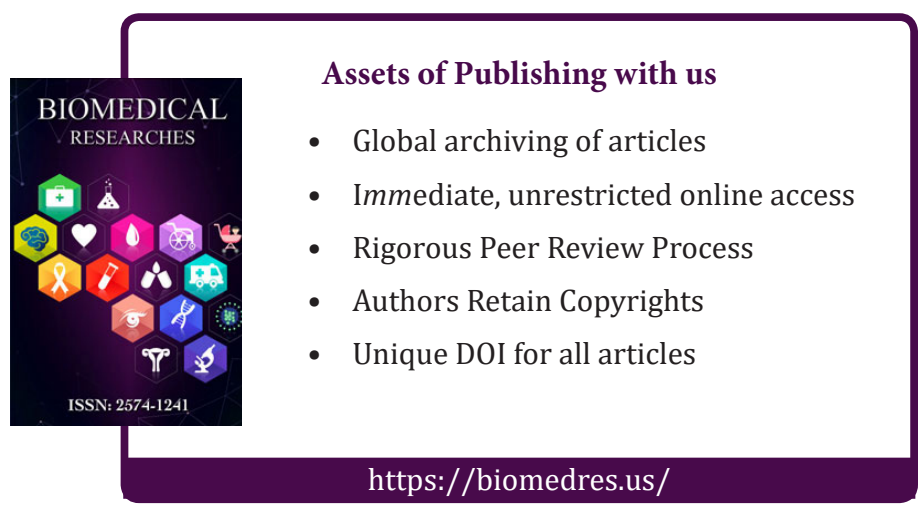

